\title{
Lusaka Central Zone Teachers' Perspectives on Continuing Professional Development
}

\author{
Josephine Kabila $^{1^{*}}$, Anolt L. H. Moonga ${ }^{2}$, Mirriam Sampa Moonga ${ }^{2}$ \\ ${ }^{1}$ Lusaka secondary school \\ ${ }^{2}$ University of Zambia
}

*Corresponding Author: Josephine Kabila, Lusaka secondary school, Zambia

\begin{abstract}
The study investigated Lusaka central zone teachers' perspectives of Continuing Professional Development (CPD).The study was premised on the theoretical framework of Experiential learning and situated cognitive learning characterized by the concepts of experience and reflection. The objectives of the study were to: find out the teachers' knowledge of CPD, establish the support that teachers got from CPD, determine teachers' participation in CPD and establish challenges teachers faced in CPD. The study was a survey design whose population included all the four secondary schools in Lusaka central zone, all the teachers and administrators at the secondary schools and the District Education Standards Officer (DESO). A sample of 20 teachers and 1 administrator from each school and the DESO making a total of 84 respondents was selected purposively. Interviews and Focus Group Discussions (FGDs) were used to collect data from administrators and teachers respectively. Data was analysed inductively by recording the responses from the (FDGs) and interviews into common themes. The findings of the study reviewed that teachers in Lusaka Central Zone (LCZ) had knowledge of CDP and received some support in their teaching through CPD. Teachers participated as participants and facilitators. However, not all teachers participated in CPD. The challenges teachers faced in CPD included their lack of understanding of the concept and function of CPD, failure by CPD to create time for individual development and meet the teachers' needs, lack of variety in content and presentation of CPD materials and unfavorable meeting times and environments for $C P D$. The study concluded that teachers in LCZ were aware of CPD but had not embraced it as a viable form of in-service training because it did not lead to a credible qualification. The study recommended that; $C P D$ would flourish in LCZ when Education management at both provincial and district levels sensitize the teachers on the value of CPD; CPD should be given a utilitarian value, like making it a requirement for teachers' promotions and or merit increment in their salaries and CPD should be done when pupils are not in class to avoid losing class time. The study was significant in that its findings will provide insights to the teachers and policy makers on CPD in order to understand, appreciate and support its activities.
\end{abstract}

Keywords: Continuing Professional Development (CPD), Performance, Zone Teachers, Management.

\section{INTRODUCTION AND BACKGROUND}

Most education systems in Africa and possibly the world over have undergone continuous changes in search for relevance and improved practices. In some cases, fiscal have led to changes in the delivery of education as countries had to adjust their budgets to suit the available resources. For example, Kelly (1991) observes that Zambia experienced increasingly grave financial problems in the mid1980 s leading to a decline in the economy which affected all sectors including education. $\mathrm{He}$ contends that the deterioration occurred at a time when the population was growing at a rapid rate hence the education sector has been subjected to two opposed pressures: a fiscal pressure to curtail financial commitments and a demographic pressure to increase the provision of education. Kelly further concludes that the outcome has been a virtual stagnation in resource allocation, a substantial increase in enrollments and in consequence, a reduction in unit expenditure.

The effects of these demographic and fiscal pressures on the economy in Zambia had to be mitigated by embarking on programmes that support development of instructional materials and teacher development. The Ministry of Education (MoE,1992) reports that some of the deteriorated education system was supported by donor countries such as Finland and Sweden through the FINIDA book writing project and the Self Help Plan for Education (SHAPE) project sponsored by the Swedish International Development (SIDA).These also supported teacher development through In-service 
education at selected colleges and resource centres built around the country with aid from the United Kingdom in the Action to Improve English, Mathematics and Science (AEIMS) project which supported the development of materials in the three subjects of English, Mathematics and Science.

The Ministry of Education also acknowledged that the classroom effectiveness of teachers depends heavily on their knowledge of the subject matter and on their pedagogical skills. In this vein, the Ministry realised that teachers need to be given regular opportunities for self-improvement in both of these areas and that future programmes of in-service education needed be comprehensive and systematic. However, the Ministry was cautious that these would not be offered just for their sake, but in order to make the participants more effective as classroom teachers and hence become better equipped to bring about student learning. The Ministry of Education (MoE,1996) in Zambia, therefore, resolved that for many years to come the main purpose of in-service education would be to familiarize teachers with new curriculum content and materials, to upgrade their actual instructional skills and to promote their resourcefulness in using as teaching materials items that are available locally. For this reason, the Ministry also recognized the mammoth task involved in teacher development and therefore, adopted more practical methods of providing the much needed in-service training by using the professional networks of school inspectors and the organizational network of resource centers and resource teachers within the framework of SHAPE and AEIMS. This became the origin of Continuous Professional Development (CPD) in Zambia.

Like many countries worldwide, Zambia through the Ministry of Education has been trying to improve practice of teachers in order to have effective teaching and learning in schools. First and foremost it is acknowledged by the Ministry of Education that school based Continuing Professional Development is one of the effective ways of improving education as far as teaching is concerned (Ministry of Education, 2001). In addition, the MoE has set strategies to strengthen systems for CPD not the least being to monitor CPD activities and stakeholder workshops in the 10 provinces of Zambia. This is supervised by the District Education Standards Officer (DESO) at district level. Furthermore, CPD has been in the Ministry of Education for about a decade now and is done by teachers at zonal level and at school level in respective schools. A zone is composed of about four or five schools. Zone meetings are held at least once a term. Further, schools also are expected to conduct in-house CPDs known as school-based CPD.

In primary schools, teachers under the on-going school-based Continuing Professional Development (SBCPD) project, do lesson study (Ministry of Education, 2009). However in Secondary Schools, teachers meet in their respective subject areas at school level at least once a week to do lesson study for 80 minutes or as arranged within respective schools. This is noncredit professional growth; it can be linked to the educational reform document perspective on the point of Education for Development.

The Continuing Professional Development of teachers in Zambia is clearly supported by policy. This is attested by the national policy mission statement and the goals of the education system which state;

The Ministry of Education is to guide the provision of education for all Zambians so that they are able to pursue knowledge and skills, manifest excellence in performance and moral uprightness, defend democratic ideas, and accept the value other persons on the basis of personal worthy and dignity, irrespective gender, religion, ethnic origin, or any other discriminatory characteristics (Ministry of Education, 1996: xi).

Further the Ministry of Education policy recognizes the role of continuing development of teachers as a requirement when it states that Teacher education is a continuing process that must be extended throughout the individual's years of actual teaching.

The Ministry contends that the foundation laid in the pre-service programme may be sound and adequate as a start, but it is not sufficient for life. In specific terms, the ministry views professional development as a responsibility of all teachers for all teachers in order to deepen their knowledge, expand their professional skills and keep themselves up-to-date on major developments affecting their profession. MoE (1996) observes that education is not static, but dynamic, promoting change, in response to the needs and expectations of society, in such areas as subject content, pedagogical approaches, pastoral care for pupils, assessment procedures, school organization and management, and the relationship with parents and the community. Developments in all these aspects are under-way in Zambia's schools hence the need for teachers to be equipped with the capacity to deal with and 
incorporate them in their professional activities. Professional Development (PD) is, therefore, not limited to merely teaching and learning.

Further, MoE advances that Continuing Professional Development is viewed as critical for success in a wide range of human endeavor. In education, it has served a somewhat similar purpose, and has been applied to different educational systems as an intervention to improve effective teaching and learning. It is one of the effective ways of improving teaching through sharing of knowledge and skills among colleagues.

According to $\mathrm{MoE}$ (2010) teaching is a learned and learning profession, and every teacher should also be a learner. The Ministry contends that teachers should continuously improve their teaching methodologies and content delivery at school level since it's not possible to send all teachers for inservice training to colleges universities. In Zambia, the Ministry of Education has further acknowledged that the main business of the school is that of teaching and learning and teachers are an important factor in bringing about improved learning and achievements in pupils. As such the teacher's professional needs should be addressed adequately if the desired pupil performance level has to be attained. Teacher knowledge, competences are vitally important in enhancing pupil performance (ibid).

Banda (2014) argues that demand for investment in research in professional development of teachers and teacher education in general has increased and the momentum has increased in the last decade or so. However, he revealed that Zambia and other African countries showed little activity and unsustainable systems at the time of his study. But we can arguably say Zambia is aware of the fast changes that should be done in order to, first of all, have the Millennium Development Goals (MDGs) met and later be ready for the Sustainable Development Goals (SDGs).In fact, he contends Zambia seems ready to embrace the global trends by even further institutionalizing CPD in the teaching training colleges. School-based CDP aims to improve teaching and learning activities in the classroom through lesson study by strengthening CPD activities of all subjects or learning areas at school and college level (ibid).

We have noted that Banda's study focused on explaining the theoretical explanation on teacher professional growth through owned and sustainable INSET system in developing countries like Kenya, Malawi and Zambia. These had undergone several policy reforms in the area of INSET and at the same time had minimal sustainability, the present study aimed at exploring potentialities of Continuing Professional Development in order to establish whether it could promote action research among teachers in Lusaka central zone of Lusaka District in Zambia.

We are not overlooking the well-known fact that the work of teaching has always been difficult and demanding. We are fully aware as Mc Niff (2001) observes that nowadays, it isn't just the demands of the classroom that are wearing teachers down, student's problems; parental and societal expectations keep increasing; and financial cutbacks made it clear that today's teachers are being asked to do more with less. He further supposed that worse still, the respect and regard that the society had traditionally placed upon teachers is eroding. We can contentedly say Zambian teachers are not exceptional. Mc Niff further explains that teacher criticisms and attacks on the very value of a public education are becoming a regular public debate. However, under CPD there is hope that motivation can be enhanced by empowering reams of colleagues who share a passion about one facet of teaching and learning to conduct investigations into that area of interest and then share what they have learned with the rest of the school community. This strategy allows an entire faculty to develop and practice the discipline that Senge (1990) considered as "team learning". While the goal of education as outlined in the policy document is clear in support of INSET (MoE, 1996) the goal of school-based CPD through lesson study is to realize a learner centered lesson by applying multiple teaching/learning approaches to the learners (MoE, 1996 and MoE 2010).

Banda (2014) agrees with Feiman-Nemser (2001) and UNESCO (2011) that if schools offer quality teaching and learning opportunities for students, quality learning for teachers should be made available. They further suggest that such opportunities should be grounded in a conception of learning to teach a lifelong endeavor and designed around a continuum of teacher learning.

Similarly, in the country of Malta, a new curriculum framework had to be designed in order to accommodate the challenges faced by the education system. Cristina (2012) observed that this led to education authorities and teachers to make decisions to measure successes and failure at the micro 
level of their schools on a regular basis. She further reports that the strengths and weaknesses of that country's curriculum framework will have to be regularly monitored.

Mutambo (2016) observes that in the United Arab Emirates (UEA) it is required that every school constantly holds Professional Developments (PDs) for both administrators and teachers on the annual plan. She reports that every public and private school in the UAE is required by the Ministry of Education to get accreditation from the UAE Commission of Academic Accreditation (CAA). One of the main criteria that the CAA emphasises when going over teachers profiles are whether the teachers in a particular school has been attending PD workshops.

CPD is also used in other professions such health and engineering for the advancement of the professionals. According to the Appraisal Institute of Canada (AIC) (2017) members are required to complete credits as part of their CPD programme. In January, 2014 the Appraisal Institute of Canada introduced a two year CPD cycle for designated and candidate members. This means that CPD credits earned by members were deemed relevant the certification or general upgrade of the candidate.

In the United Kingdom, the Royal College of General Practitioners (RCGP) uses the credit based mechanism for recording CPD based on the time spent on an activity and the impact on the trainee (doctor) on his or her patients and the service. In this respect we can see that CPD is used as a measure to determine the professional advancement of the trainee or practitioner. In the guidelines of the RCGP the appraisal process of the trainee underpins revalidation and enables the general practitioners to demonstrate through the collection of a single portfolio of evidence of (CPD) that they meet the required standard (RCGP, 2017). Further, RCGP admonishes general practitioners that CPD is central in their learning, "maintaining your knowledge up to date through CPD is a professional responsibility"(www.rcgp.org,uk/learning/cpd-credits-and appraisal.aspx.).

In Australia the Psychology Board of Australia (PBA) (2012) released a draft sheet on Continuing Professional Development giving standard for public consultation. Among other things the board outlines five key information facts about CPD and the steps practitioners need to complete their CPD namely;

- identify one's registration status and CPD requirements

- develop one's learning plan

- undertake CPD

- maintain one's CPD portfolio

- renew one's registration

CPD therefore according to the Psychology Board of Australia is the means by which members of the profession maintain, improve and broaden their knowledge, expertise and competence, and develop the qualities required in their professional lives. It is an on-going process which continues over the course of a career, adapting to changes in practice environment, professional domains, new information and consumer needs. Carefully tailored CPD can assist competency and relevancy in practice, which in turn assists members of the public (www.psychology.org/au/asserts/fact-sheet-cpd).

We have seen that CPD therefore, is a very important professional activity in all careers. This study focused on CPD as it is used in the teaching learning environment among teachers in Lusaka Central zone in Zambia.

\subsection{Definition of Continuous Professional Development (CPD)}

Kabila (2015) records that CPD is known to be in three ways: Professional Development (PD), Continuing Professional Learning (CPL) and Continuing Professional Development (CPD). Some scholars have found these terms often with overlapping meanings. We will, however, agree with Bolam and McMahon (2004) that the term continuing professional development be used because it distinguishes the development of teachers throughout their career, which is the focus of this study .CPD therefore, is defined differently by different professions and the definitions largely depend also on the context in which it is used. For example, in the teaching profession, Continuing Professional Development may refer to programmes and strategies designed to change the beliefs and practices of teachers in order to improve the achievement of their students (Guskey, 2002). Virginia and Laughridge (2011) cite several authorities on professional development and its role when they state 
"School reform has been impacted by the demands of NCLB. These demands include accountability for educators at all levels. Accountability for school reform is especially true for leaders in professional development who have to meet the requirement for "scientific", researched-based programs with a strong emphasis on student improvement (Guskey, 2003a). The recent trends in educational professional development encompass structured activities or courses in the workplace to enhance professional skills of educators, keep the educators up-todate or to support change in the organization (DalleAlba\& Sandberg, 2006). Guskey (1986) and Hashweh (2004) describe professional development as a systematic attempt to bring about change. Guskey (1986) and Griffin and Barnes (1986) specifically describe the change components: (a) change in the classroom practices of teachers, (b) change in teacher's beliefs and attitudes, and (c) change in the learning outcomes of students".( p.4).

This demonstrates that Professional Development in education plays a central role in the teaching and learning activities of a school. Both the learners and the teachers stand to benefit from the activities of CPD. Hardy and Wagga(2009) observe that Professional Development is an integral part of the life of schools and teachers, is an important mechanism to ensure educational reform and improvement in school settings.

The Register of Exercise Professional (REP) defines CPD as a way for exercise professionals to demonstrate that they continue to learn throughout their careers, to keep their skills and knowledge up to date and are able to work safely, legally and effectively (www.exerciseregister.org/cpd-trainingcpd). This shows that CPD goes involves more than just the teaching profession. Whereas the concept and purpose of CPD might be the same, different professionals use CPD for different purposes. What underlines all is the professional development of the practitioner in one's career. The present study examined the teachers in Lusaka Central Zone and how the perceive CPD.

\subsection{Statement of the Problem}

In Zambia, the policies on education acknowledge CPD as an integral part of teaching and learning in the school system. MoE (1992, 1996 and 2010) contend that teacher education is a continuing process that must be extended throughout the individual's years of actual teaching. The Ministry also believes that the foundation laid in the pre-service programme may be sound and adequate for a start, but it is not sufficient for life. Although this stance is indicative of the need and value of CPD in education, the Zambian teachers' perspectives on CPD were not known. This warranted a study to investigate the perspectives of teachers in Lusaka Central zone on Continuing Professional Development.

\subsection{Research Objectives}

The objectives of the study were to;

- find out teachers' knowledge of CPD

- establish the support that teachers get from CPD

- establish teachers participation in CPD

- determine challenges faced by teachers in CPD .

\subsection{Research Questions}

- What knowledge do teachers have about CPD?

- What support do teachers receive from CPD?

- What is the teachers' participation in CPD like?

- What challenges do teachers face in CPD?

\subsection{Significance of the Study}

The findings of this study are significant in that the stakeholders in education in general and teachers in particular will through the findings learn the views of the clients in CPD which should help to improve their delivery and mastery of content in teaching. The Ministry of education will also be guided on the need to utilize all teachers in the delivery of CPD materials in order to remove the notion of inferiority complex and unwarranted claim of expertise by a small section of the teachers. 
Teachers will realize that CPD is directed at benefitting all of them in one way or the other and this will encourage all the teachers to participate in CPD. Through participation and sharing of resources, skills and knowledge among teachers and administrators and subsequently a more conducive teaching and learning environment which is a pre requisite for attainment of quality education will be created. In this way the findings of this study will help to improve insights of teachers and policy makers on CPD.

\section{Summary OF The Methods USED}

The study was a survey of perspectives by teachers' in Lusaka central zone towards CPD. The population of the study included all the four schools, all the teachers, all the administrators in the zone and the District Education Standards Officer (DESO).Out of the total population of 160 teachers, 80 were randomly sampled to include presenters and participants in CPD sessions.

Four administrators were purposively sampled to represent each school. A sample of 20 teachers and one administrator from each school were selected using purposive sampling. The teachers were either participants or presenters in CPD sessions while the administrators were school managers. The DESO was purposively sampled as the monitor or inspector of standards in the district. The total sample was 80teachers who were met in focus group discussions (FGDs).Administrators at the four schools and the DESO were interviewed separately. The nature of this study required that the views of teachers in Lusaka district central Zone were recorded hence the use of qualitative design exclusively. Data analysis was also done using qualitative method of extracting appropriate themes.

\section{SuMMARY OF FINDINGS}

The findings of the study reviewed that teachers in the central zone of Lusaka had knowledge of CPD since they participated in CPD sessions at school and zonal levels but their knowledge varied. Some of the teachers, among them those with degrees indicated that they had been involved in facilitating in CPD sessions. Even those that had not been facilitating in the sessions admitted having attended CPD meetings.

Although some teachers with degree qualifications felt that they had little to learn from CPD, many of them received a lot of help from CPD. One of them stated "I had problems in teaching summary at secondary school but after listening to colleagues and how they teach summary I adopted some of the approaches and have since become confident in handling it".

Some teachers in science and mathematics made similar observations. It is therefore clear that the findings reviewed that teachers got support from CPD. Further the District Standards Officers reviewed that they use CPD guidelines in their monitoring work. This means that teachers are expected to comply with the standards expected of them by the system to ensure quality education is attained.

Most of the teachers in Lusaka zone indicated that they participated in CPD sessions as this was a requirement by the school management. Teachers who did not participate in CPD sessions were reproached by their supervisors. As indicated earlier, teachers participated in CPD both as participants and as facilitators.

The study findings reviewed that teachers in Lusaka central zone faced challenges with CPD. Some of these included the monotonous nature of the content and delivery styles. Some teachers observed that the presentations were repetitive and lacked creativity. This brought in some challenges as some teachers felt that their facilitators were not well qualified. Another group felt that some facilitators lacked the experience of instructional design and delivery.

"The trouble with these CPD sessions is that they focus on the same topics and presented by the same people. Some of whom do not have the skill and qualification in instructional design and delivery. This tends to be boring and predictable," One teacher said.

"There is lacks variety since the school does not have enough books to refer to and some of the presenters are not well qualified. Everything is as it was presented the previous time," said another teacher.

The teachers also found CPD as an inhibition of their personal progress and development. This frustrated the qualified teachers who were not picked to facilitate. On the other hand when a teacher 
with a degree qualification was asked to facilitate, they would be ridiculed by the other teachers as they would be considered to be showing off.

It was done at wrong times like during break time and other free periods and sometimes even at weekends and during holidays when teachers needed to rest or do any other personal jobs. They contend that CPD infringed on their freedom and exhausted their energy creating an unconducive environment in the school. Teachers indicated that the free periods and break in the school are intended for them to recoup their energy and do other things such as marking and lesson planning. When this time is taken by CPD it meant that teachers had to find other times such as in the evening at their homes to do what they should have done at school. Sometimes teachers would fail to carry out other economic activities like gardening and poultry because of time spent on CPD. Further, the findings reviewed that teachers considered CPD as a waste of time since it did not lead to any acceptable accreditation in the country. Several teachers indicated that CPD should be used as criteria for promotion and other internal rewards. In some cases teachers had to meet their own costs of travel and upkeep to participate at zonal or interschool CPD meetings.

The manner in which CPD is used in Australia, Canada, and United Kingdom where it clearly adds to one's professional advantages development is good. The same should be made clear in Zambia as to what advantages one can get from CPD. The pattern or model of the United Arab Republic where CPD contributes to one's promotion at work is another avenue that can encourage teachers to participate in its activities.

It has become clear that the real benefits of CPD had not been made clear to the teachers in Lusaka Central Zone. A policy direction in this manner would help to popularize CPD and enable the teachers to participate.

\section{CONCLUSION}

Having looked at the summary of the findings it can be concluded therefore that teachers in Lusaka central zone were aware of the existence of CPD and its activities in the schools. It can also be concluded that teachers received support from CPD in various ways. Some of teachers discovered new and better methods of handling topics in class. The study concludes that teachers participated in CPD as participants and facilitators. However, this became a point of frustration for those who were not given the opportunity to facilitate. Finally, the study concluded that teachers met a lot of challenges in CPD. These range from the design, content management and facilitation of CPD.

\section{RECOMMENDATIONS}

This study recommended that:

For CPD to flourish in Lusaka central zone, Education management at both district and school levels should sensitize the teachers on its value in the professional development of teachers.

CPD should be supported by good supply of teaching /learning resources which will enable teachers to discover and design new instructional material, methods and techniques to share with colleagues. This will enhance the teaching and learning activities at all levels.

CPD be made attractive to all teachers to participate in by making it a requirement for teacher promotion so that teachers can be motivated to attend CPD sessions. CPD should be made to count as a recognized qualification for those who have attended and facilitated a given number of sessions.

CPD should be well enshrined in the school curriculum to enable participants to accommodate it in the school activities. It must be a funded activity for those who are going to participate in CPD meetings outside the school.

The study further recommends that another research be done on the impact of CPD on teaching and learning practices in the classroom in Zambia.

\section{REFERENCE}

[1] Appraisal Institute of Canada (2017). Continuing Professional Development. AIC: Ottawa

[2] Banda, B. (2014). Continuing Professional Development through Sustainable In-service Teacher Training System in Kenya, Malawi and Zambia. : Retrieved March 18, 2015, from. Berlin: Technische Universität. Retrieved March Wednesday, 2015, from https:/opus4.kobv.de/opus4-tuberlin/frontdoor/index/ index/ docId/ 5125. 
[3] Bolam, R and McMahon (2004). Teaching: Professionalization, Development and Learning in Professional Learning Communities and Teacher's Professional Development. Amstedam: Springer

[4] Cristina, D. (2012). National Curriculum Framework for all. Malta: Ministry of Education and Employment.

[5] Hardy.I\&Wagga,W.(2009).Teacher Professional Development:A Sociological Study of Senior Educators' PD Priorities in Ontario. CANADIAN JOURNALOF EDUCATION32, 3:509-532

[6] Guskey, T. (2002). Professional development and teacher change. Teachers and teaching: theory and practice. Vol.8, No:3/4.

[7] Kabila, J. (2015). Teachers' views and perspectives on Continuing Professional Development based on Action Research: A case study of Lusaka central cluster, Zambia. Ireland: UCD. Un published

[8] Kelly, J. (1991).Origins and Development of Education in Zambia. Lusaka: Image Publishers.

[9] Virginia, J \&Laughridge,V.J.(2011). The Relationship between Professional Development and Teacher Change in the Implementation of Instructional Strategies that Support Elementary Students' Science Textbook Reading University of Nebraska. http://digitalcommons.unl.edu/cgi/viewcontent.cgi?article $=1010 \&$ context $=$ teachlearn student

[10] Ministry of Education, (1992). Focus on Learning. Lusaka: Ministry of Education.

[11] Ministry of Education. (2001). School-Based continuing Professional Development (SBCPD) through lesson study: Teaching skills Book (1st ed.). Lusaka: Ministry of Education.

[12] Ministry of Education. (2010), JICA. (2010). School-Based continuing Professional Development $(S B C P D)$ through lesson study: Teaching skills Book (4th ed.). Lusaka: Zambia.

[13] Mutambo, E.N (2016). The impact of teacher Professional Development Workshops: and teacher professional development courses run by the Al Qasimi Foundation in the Ras Al Khaimah Education Zone, in the United Arab Emirates. Unpublished.REPS (2017). What is CPD? (www."-exerciseregister. org/cpd-training-cpd

[14] Royal College of General Practitioners(2017). RCGP Learning. Essential CPD for primary care. (www.rcgp.org,uk/learning/cpd-credits-and appraisal.aspx

\section{AUTHOR'S BIOGRAPHY}

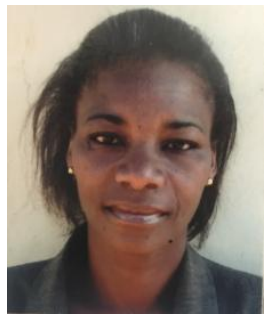

Ms. Josephine Kabila is a teacher at Lusaka Secondary GRZ. She holds a Master's degree in Education from Ireland. She also holds a Bachelor of Adult Education from the University of Zambia. She has interest in research particularly on issues of education AND Teacher education.

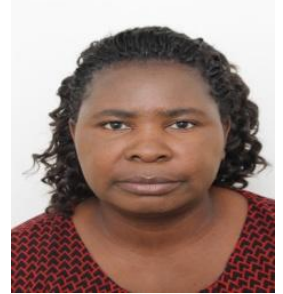

Mrs. Mirriam Sampa Moonga is a lecturer in Environmental Education at the University of Zambia. She holds a master's degree in Environmental Education and has presented several papers on issues of the environment around the world. She, however, has interest in issues of teacher development and education in general.

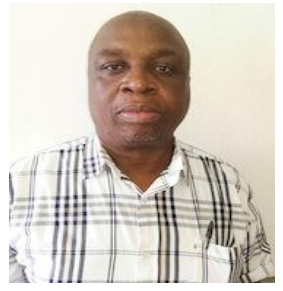

Mr, Anolt L.H.Moonga is a Lecturer in the Adult Education department of the University of Zambia. He has a master's degree in Education and has researched and published in adult education and Teacher education. He has also written books on English for the Senior Secondary school course in Zam

Citation: Josephine Kabila, Anolt L. H. Moonga, Mirriam Sampa Moonga. “Lusaka Central Zone Teachers' Perspectives on Continuing Professional Development". International Journal of Humanities Social Sciences and Education (IJHSSE), vol 5, no. 6, 2018, pp. 15-22. doi: http://dx.doi.org/10.20431/2349-0381.0506003.

Copyright: (C) 2018 Authors. This is an open-access article distributed under the terms of the Creative Commons Attribution License, which permits unrestricted use, distribution, and reproduction in any medium, provided the original author and source are credited. 